\section{Slavko Arsovski ${ }^{1}$}

\title{
QUALITY OF LIFE AND SOCIETY 5.0
}

Abstract: In Japan is process for achieving a ,Super-Smart Society" as fifth stage of society`s development. It is natural extension of today's Information Society (Fourth stage) wich includes Germany`s „Industry 4.0“vision.

Through analysis elements of Society 5.0 are emphasized four main carracteristics: (1) optimising society as a whole with integration of cyber space and physical space, (2) using data as a new resource, (3) realising in environment with change and constraints, and (4) solving complex social and living problems. All of them and esspecialy the last one is related to Quality of Life (QoL).

In the paper are presented structure and requests related to Society 5.0, as well as new model of QoL and relationships among them.

Keywords: Quality of Life, Quality, Society 5.0, Smart Society

\section{Introduction}

The Society 5.0 concept is developed in Japan over a five-year term, based on a 10year forwar outlook. The Fift Science and Technology Basic Plan (CSTI, 2016) until year 2020 has 7 chapters, i.e: (1) recognition of current situation, achievements and challenges in previos years, target national profile, and basic pillars and important issues in the promotion of Basic Plan, (2) acting to create new value for the development of future industry and social transformation through: (a) fostering $R \& D$ for the future and (b) realizing ,supper smart Society“ with appropriate service platform, (c) enhancing competitiveness and consolidating fundamental technologies in Society 5.0, (3) adressing economic and social shallenges with: (a) sustainable growth and selfsustaining regional development, (b) enchancement of higher QoL through safety and security and high quality and prosperious way of life, (c) adressing global challenges and contribution to global development, (4) reinforcing the „fundamentals“ for Science, Technology and Innovation-STI through: (a) developing high-quality human resources, (b) promoting excellence in knowledge creation, and (c) strengthening funding reform, (5) establishing a systemic virtuous cycle of human resources, knowledge and capital for innovation through: (a) enhancing mechanisms for promoting open-innovation, (b) enhancing the creation of SME and Start up companies to tacle new business opportunities, (c) strategic use of Intellectual Property (IP) and standardisation, (d) reviewing and improving the regulatory environment for innovation, (e) developing innovation systems that contribute to „regional revitalization“, and (f) cultivating opportunities for generating innovations in anticipation of global needs, (6) deepening the relationship between STI and society, and (7) enhancing capacity to promote STI.

For our research in focus are first five chapters in action plan which are diecly

\footnotetext{
${ }^{1}$ Corresponding author: Slavko Arsovski Email:_cqm@kg.ac.rs
} 
connected with QoL (table 1). Besides narrow relations between chapter 3 and social impact of QoL in this matrix are included elements of concepts of ,future city“ (Japan's Future city initiative, 2012), digitalization and optimization of all urban activities (Keidanren, 2017), innovation (Ozkeser, 2018), ,smart community“ (JSCA, 2015), next-generation smart city initiatives, an University role in Society 5.0 (Harayama, 2017), and concept of „Platinum Society“ (Kamiyama, 2015).

\section{Basic of society 5.0}

The Society 5.0 in Japan started with five basic Plans regarding S\&T (Science and Technology). Each Basic Plan was spend five years from starting year 1996. The last Basic Plan is in progress (2016-2020). It has four fundamental Themes (CSTI, 2018), i.e.: (1) create new value for the development of future industry and social transformation, (2) address economic and social challenges, (3) reinforce the fundamentals of STI, and (4) establish a systemic cycle of human resources, knowledge, and capital for innovation. For it is planned investment of at least 4\% of GDP (for public and private sector) and at least $1 \%$ of GDP for genernmental investiment in R\&D.

In concept „Society 5.0“ all necessary goods and services will be provided to enybody at any time and at any place regordless of region, age, gender, language or other limitation. The main gooal of "Society 5.0“ is to achieve ,economic growth/well-being and overcome societal challenges at the same time, contributing to the prosperity of global communities (CSTI, 2018).

The concept of „Society 5.0“ consists from four important systems:

1. common basic functions,

2. ICT on upper level,
3. basic cyberspaces technologies as AI, „Big data analysis“ etc as pilar, and

4. incorporated social and production systems.

The common basis functions consists from:

- promotion of IP strategies and International Standardisation,

- promotion of Regulatory and institutional Reforms and Cultivation of Social Acceptance, and

- Promotion of Capacity Development and Personal Training.

The ICT consists from different Data Based regarding:

- population, commodities, and vehicular information,

- medical information,

- global environment infrastructure,

- information to facilitate the circulation of data between different industries,

- energy demand and supply data,

- 3D Mapping Information,

- Satelite observation data,

- visual information.

The pilar regarding Basic Cyberspace Technologies is base for interconnected different systems, i. e.:

- smart agricultural production system,

- smart food chain system,

- integrated materials development systems,

- new business and services,

- hearty hospitality system,

- integrated community care system,

- disaster, prevention and mitigation system,

- infrastructure maintenance and renovation system,

- intelligent transport system,

- energy value chain system,

- new manufacturing system, and 


\section{International Cualíly Conference 13.}

- global environment information platform system.

Also, in this level are included concepts and other systems as:

- smart cities and regions,

- smart tourist destination and tourism,

- knowledge economy,

- cultural and creative cities,

- smart government,

- smart people through smart specialisation,

- smart environment, etc.

Many components of "Society 5.0" is connected with Quality of Life (QoL) according to table 1 .
Table 1. Relations among Society 5.0 and QoL

\begin{tabular}{|c|c|c|c|c|c|}
\hline 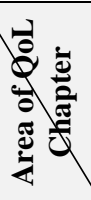 & 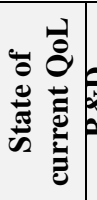 & 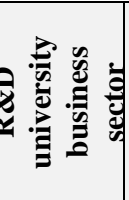 & 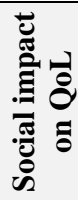 & 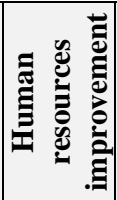 & 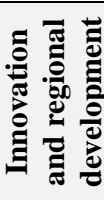 \\
\hline 1. & $\bar{\checkmark}$ & $\overline{\bar{v}}$ & $\overline{\bar{l} \checkmark}$ & $\bar{\nabla}$ & $\bar{\nabla}$ \\
\hline 2. & & $\checkmark$ & $\checkmark$ & $\checkmark$ & $\checkmark$ \\
\hline 3. & & & $\checkmark$ & & $\checkmark$ \\
\hline 4. & & & & $\checkmark$ & $\checkmark$ \\
\hline 5. & & & & & $\checkmark$ \\
\hline
\end{tabular}

\section{Integration of QoL into "Society 5.0"}

The concept of „Society 5.0" is kind of a"hyperconnected Society" (Vermesan \& Fries, 2015). Base for it is Internet of Things Integration (figure 1).

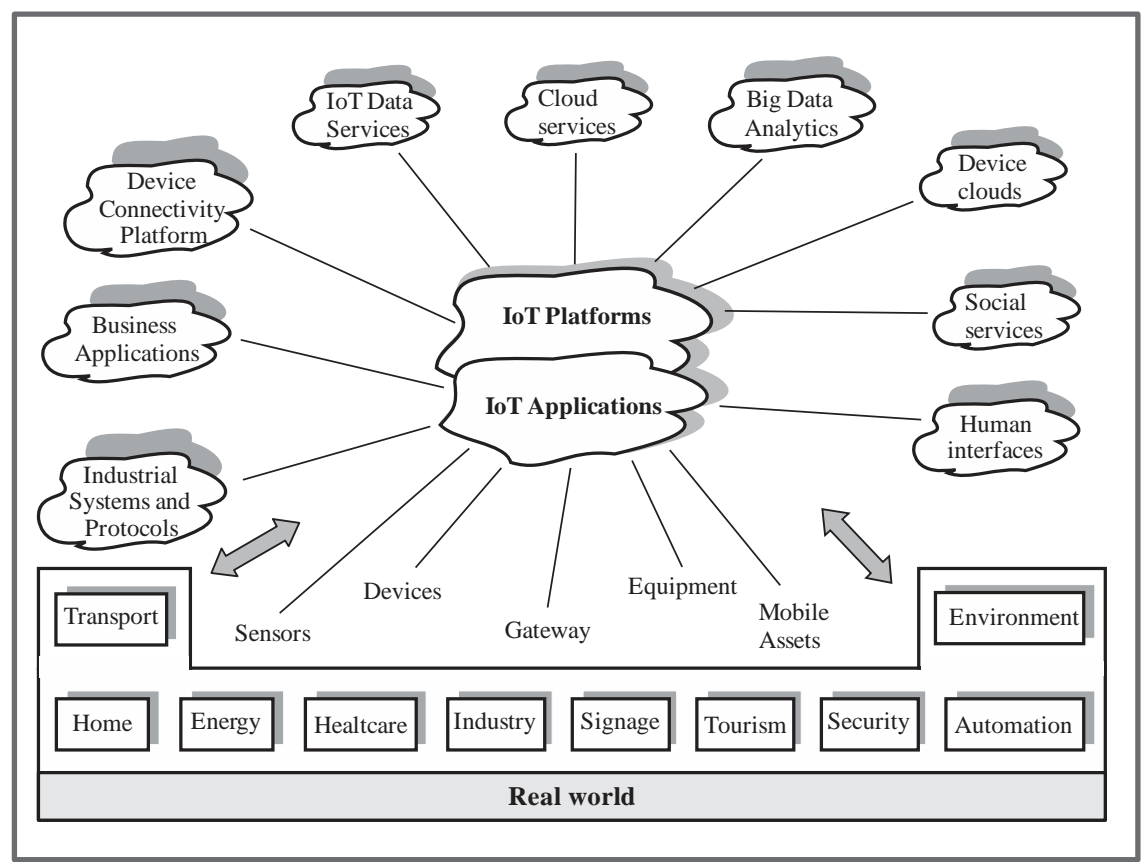

Figure 1. Internet of Things Integration (revised (Vermesan \& Fries, 2015) pp.16)

A QoL concept is until now developed for Real World. It is used Business Applications for calculating levels of QoL components and finding relationships among them (Abd-
Elrahman, 2012). The IoT concept can include data and QoL applications regarding: 
- predictive analytics based on AI and other appropriate methods and tools,

- prescriptive analytics for forseling analysied problem,

- descriptive analytics for problem analysing,

- monitoring of QoL and its components, and

- control and optimisation.

- It is based on four main Big Data properties (Vermesan \& Fries, 2015), pp.233 related to:

- volume: Data at Rest-Terabyte to exabytes of existing data to process,

- velocity:Data in Motion-Streaming data, miliseconds to seconds to respond,

- variety: Data in Many FormsStructured, unstructured, text, multimedia,

- veracity:Data in Doubt-Uncertainty and due to data inconsistency and incompleteness, ambiquities, latency, decaption, model approximations, etc.

A Big Data Analysis covers two sub-systems i.e.:

- Big Data Analytic and Knowledge Generation and

- Knowledge Based Planning and Decision Making.

- Based on previos components is desigred IoT Big Data Analytic Platform as answer on folloving requirements:

- to be intelligent and dinamic,

- based on distributed information processing,

- to be scalable and flexible,

- data processing in real-time,

- interoperability among heterogeneous devices and software,

- supporting security and privacy, and

- based on Cloud-based IoT.

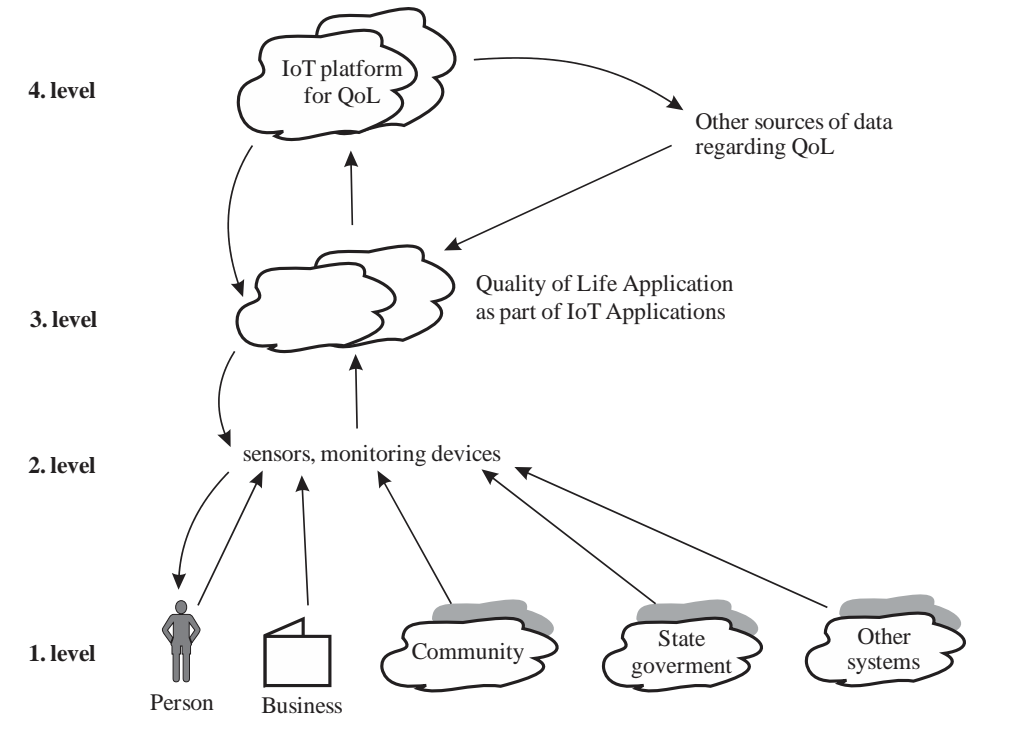

Figure 2. Structure of IoT Platform for QoL 


\section{Interinational Qualitity Conference 1 :}

According previos analyses of the concept „Society 5.0“ with included Data Analytic Platforms and QoL is posible inuidiately monitor state of each person, business systems and society as whole and provide access to Big Data Analytic Platform (figure 2 ) and calculate QoL and its analytics. In this model on first level are processes related to persons, business, communitics, state goverment, and others. Using sensors and monitoring devices at 2 . level and input devices from 1. level is performant Big Data and save it in appropriate Data Bases

On 3. level is QoL Application as part of IoT Aplications. Besides Big Data from 2. level in it access other data regarding QoL from other sources, as literature, research, etc. On 4. level is IoT Platform for QoL described in previos chapter.

Proposed model helps to solve big problems in QoL research related to:

- different models,

- access to data sources,

- real-time QoL monitoring,

- real-time decision based on AI,

- informing all stakeholders about QoL, etc.

Integration of QoL and Society 5.0 on conceptual level is presented in figure 3.

Because smart concepts incorporated into smart living, smart transport, smart education, smart health, etc. QoL approach has to be incorporated in context of smart society, as most general concept. In future with faster and broader incorporation of smart solutions, based on QoL and sustainablity, we can expect realization of full integration of QoL and Society 5.0 in QoL/Society 5.0 concept.

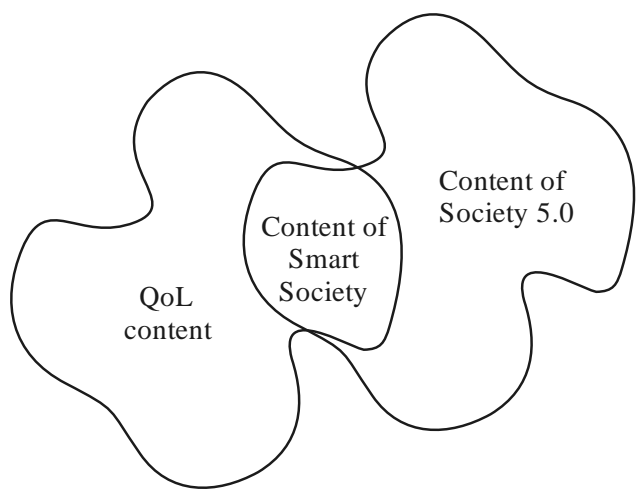

Figure 3. Integration of QoL/Society 5.0

\section{Conclusion}

The needs of present and future habitans are fast changing based on QoL approach. On other side, fostering industrial revolution to Industry 4.0 and Industry 5.0 is not enough. Now is necessary to integrate these concepts into one integrated QoL/Society concept.

\section{References:}

Abd-Elrahman, A.H. (2012), "Measuring Service Quality and Its Impact on Relationship Quality with the Customers and Their Loyalty to theOrganization", Master thesis, Productivity and Quality Institute, TheArab Academy for Science \& Technology and Maritime Transport, Cairo, Egypt.

CSTI (2016). Outline of the Fifth Science and Technology Basic Plan, Japan Government

CSTI (2018) Society 5.0 and MEMS, Bureau of Science, Technology and Innovation, Japan

Future City Initiative (2012). Cabinet Secretariat Government of JAPAN

Harayama Y. (2017). A living Concept "Society 5.0" and the role of Universities, Council for Science, Technology and Innovation, Japan

JSCA (2015). Smart Community - Japan's Expirience, Japan Smart Community Alliance

Keidanren (2017) Revitalizing japan by realizing Society 5.0: Action plan for creating the Society of the Future - Japan Business Federation (Keidanren) 
Q UA IIII I I

DIFSIFADODE

Komiyama H. (2015). The Platinum Society" of Energy Self-Sufficiency Is Approaching in Japan, Japan SPOTLIGHT, pp. 26-29

Ozkeser B. (2018). Lean Innovation Approach in Industry 5.0, The Euroasia Proceedings of Science, Technology, Engineering \& Mathematics, Vol. 2, pp. 422-428.

Vermesan D., Fries P. (2015). Building the hyperconnected society: IoT Reearch and Innovation Value Chains, Ecosystems and Markets, River Publishers Series in Communications, Vol. 43, Denmark

\section{Slavko Arsovski}

University of Kragujevac,

Faculty of engineering

Kragujevac,

Serbia

cqm@kg.ac.rs 